\title{
Damage Induced by Neutron Radiation on Output Characteristics of Solar Cells, Photodiodes, and Phototransistors
}

\author{
Biljana Simić, ${ }^{1}$ Dejan Nikolić, ${ }^{1}$ Koviljka Stanković, ${ }^{1}$ \\ Ljubinko Timotijevic, ${ }^{1}$ and Srboljub Stanković ${ }^{2}$ \\ ${ }^{1}$ Faculty of Electrical Engineering, University of Belgrade, Bulevar kralja Aleksandra 73, 11000 Belgrade, Serbia \\ ${ }^{2}$ Vinča Institute of Nuclear Sciences, University of Belgrade, Mike Petrovica Alasa 12-14, 11000 Belgrade, Serbia \\ Correspondence should be addressed to Koviljka Stanković; kstankovic@etf.rs
}

Received 27 March 2013; Accepted 9 May 2013

Academic Editor: Predrag Osmokrovic

Copyright ( 2013 Biljana Simić et al. This is an open access article distributed under the Creative Commons Attribution License, which permits unrestricted use, distribution, and reproduction in any medium, provided the original work is properly cited.

\begin{abstract}
This study investigates the effects of neutron radiation on $I-V$ characteristics (current dependance on voltage) of commercial optoelectronic devices (silicon photodiodes, phototransistors, and solar panels). Current-voltage characteristics of the samples were measured at room temperature before and after irradiation. The diodes were irradiated using Am-Be neutron source with neutron emission of $2.7 \times 10^{6} \mathrm{n} / \mathrm{s}$. The results showed a decrease in photocurrent for all samples which could be due to the existence of neutron-induced displacement defects introduced into the semiconductor lattice. The process of annealing has also been observed. A comparative analysis of measurement results has been performed in order to determine the reliability of optoelectronic devices in radiation environments.
\end{abstract}

\section{Introduction}

Optoelectronics is at the crossroads of electronics and optics. Using optical and electronic means, it generates, manipulates, and converts light. Photonic devices process, store, transmit, and display information for applications such as communications, displays, imaging, memory, biophotonics, energy generation, and lighting. Photonics is an essential part of a country's information infrastructure, which, in turn, plays a key role in its domestic economy and national defense. Solid-state devices like sensors, IR emitters, and laser emitters are used for optoelectronic applications. Optoelectronic devices can be classified into photoconductive and photovoltaic devices. Photoconductive devices such as photoresistors are widely used in counting systems, twilight switches, house security systems, and so forth. These detect variations in the light intensities and activate or deactivate electronic circuits. Photodiodes and phototransistors also fall in this category. These utilise the reverse biased junctions for generating current when illuminated. Photovoltaic devices produce a voltage when these are exposed to light. The light energy produces a potential difference across the $\mathrm{p}-\mathrm{n}$ junction depending on the intensity of the incident light. Solar cells and photovoltaic cells are widely used in various applications to generate electricity.

One of the most specific fields of application of optoelectronic devices is the space. Possibilities of application of optoelectronic devices in this area are countless (photonic communications, photonic signal processing, photonic sensing, speciality applications, etc.). The use of optoelectronic technologies in space applications has shown an important increase in the last years due to the multiple applications and their advantages compared with standard technologies. A complete evaluation of the technology has to be performed in advance in order to select the best components and to reduce the risk of using devices that have not been designed to work in space environmental conditions. Experience shows that the evaluation of the most critical aspects reveals that not all the commercial devices that are available in the market are suitable for space use [1].

A number of researchers and institutions work hard to produce new and improve existing optoelectronic devices to be reliable and effective in specific circumstances such as space. In the space environment, optoelectronic devices 
are exposed to different types of radiation, such as protons, alpha particles, heavy ions, neutrons, gamma rays, electrons, and positrons. In previous papers, the behavior of various optoelectronic devices in terms of neutron radiation has been observed [2-9].

There are free neutrons everywhere in nature, in small amounts. Their main source is cosmic rays. They also occur in nuclear reactions of natural alpha radiation and spontaneous fission of heavy nuclei. In many ways, neutron is a unique particle-with no electric charge, it has a relatively large mass, subject to radioactive decay. Neutrons build each atomic nucleus except that of hydrogen, that is, they are the constituents of all matter. For the practice of nuclear reactions, neutrons are much more important than any other particles. Neutron, as a neutral particle, does not possess the ability for direct ionization of materials. The basic mechanism of the neutron interaction with the environment is through the elastic collision with the atomic cores of that environment. Interaction with the electrons, although exists, is negligible. Energy transfer in these collisions is executed entirely in accordance with

$$
\varepsilon_{t}=\varepsilon \frac{4 \cdot m_{1} \cdot m_{2}}{\left(m_{1}+m_{2}\right)^{2}} \cdot \sin ^{2}\left(\frac{\theta}{2}\right)
$$

where $\varepsilon_{t}$ is energy, transferred in an elastic collision, $\varepsilon$ is energy of incident particles, $m_{1}$ is incident particle mass, $m_{2}$ is struck particle mass, and $\theta$ is angle between the direction of scattering of incident particle and the direction of intrusion. Thereby, the neutron loses some of its energy and slows down, while the environment may suffer from different types of transformation.

Neutrons and other high-energy particles collide and displace lattice atoms in semiconductors, creating Frenkel defects. Primary displaced atoms typically have enough energy to create secondary defects. These vacancies may combine with dopant and impurity atoms to form stable defects, which, in turn, may serve as recombination centers, decreasing carrier lifetime. The decrease in carrier lifetimes in doped semiconductor materials after exposure to a neutron fluence has been characterized as an abrupt decrease followed by a rapid short-term anneal (on the order of a few hours) and a long-term anneal (on the order of months), in which the carrier lifetime increases [10]. Axness et al. [11] show that the lattice damage and carrier lifetime degradation are spatially dependent.

This work describes a series of measurements undertaken to try to identify the similarities and differences in behavior of solar cells, photodiodes, and phototransistors in situation when these have previously been damaged by neutron radiation and have had enough time to recover. The aim of this paper is to provide readers with a comparative overview of the processes that occur in solar cells, photodiodes, and phototransistors after neutron irradiation and to give a critical review of the effectiveness of these devices in the environment with neutron radiation, that is, space.

\section{Materials and Methods}

Experimental measurement in this paper was carried out on the commercially available optoelectronic devices. In this experiment, the following were used:

(1) monocrystalline silicon solar panel (maximum power voltage $4.0 \mathrm{~V}$, maximum power current $100.0 \mathrm{~mA}$, dimension: $70 * 65 * 3.2 \mathrm{~mm}$ );

(2) four types of silicon PIN photodiodes (BP104, BPW41N, BPW34, all manufactured by Vishay, and SFH203FA by Osram);

(3) two types of silicon NPN phototransistors (BPW40 manufactured by Telefunken electronic and LTR4206 by Liteon).

Semiconductor devices have been exposed to neutron and gamma radiation from ${ }^{241} \mathrm{Am}$-Be source, which is housed in the Secondary Standard Dosimetry Laboratory (SSDL) Institute of Nuclear Sciences "Vinča," Belgrade. ${ }^{241} \mathrm{Am}-\mathrm{Be}$ source emits gamma photons of low energy $(60 \mathrm{keV}$ and $14 \mathrm{keV}$ ), so that for the activity of $1 \mathrm{Ci}$, the photon equivalent dose rate is $\dot{H}_{\gamma}=12 \mathrm{mSv} / \mathrm{hr}$ are calculated, and the photon absorbed dose rate is $\dot{D}_{\gamma}=12 \mathrm{mGy} / \mathrm{hr}$ at a distance of $5 \mathrm{~cm}$ from the source. The intensity of the neutron emission from this source is $2.7 \times 10^{6}$ neutrons s ${ }^{-1}$, and the mean energy of the neutrons $E_{\text {nav }}=5.5 \mathrm{MeV}$. Based on measurements of the quality factor for this neutron spectrum $Q_{n}=7$, calculated the neutron absorbed dose rate $\dot{D}_{\mathrm{n}}=1.714 \mathrm{mGy} / \mathrm{hr}$ and the equivalent dose rate of neutrons $\dot{H}_{\mathrm{n}}=12 \mathrm{mSv} / \mathrm{hr}$. This means that at $5 \mathrm{~cm}$ distance from the ${ }^{241} \mathrm{Am}$-Be source with a total absorbed dose rate is $\dot{D}_{\text {tot }}=13.714 \mathrm{mGy} / \mathrm{hr}$, while the total equivalent dose is $\dot{H}_{\text {tot }}=24 \mathrm{mSv} / \mathrm{hr}$. In this experiment, the semiconductor devices were placed at a distance of $5 \mathrm{~cm}$ from the ${ }^{241} \mathrm{Am}$-Be source, and the exposure period was $16.75 \mathrm{hr}$. In this interval, the material components received the radiation of the total absorbed dose in the amount of $D_{\text {tot }}=229.71 \mathrm{mGy}(13.714 \mathrm{mGy} / \mathrm{hr} * 16.75 \mathrm{hr})$, and respectively, the total equivalent dose $H_{\text {tot }}=402 \mathrm{mSv}$ $(24 \mathrm{mSv} / \mathrm{hr} * 16.75 \mathrm{hr})$. The components were irradiated in the air at a temperature of $21^{\circ} \mathrm{C}$ and relative humidity of $40 \%$ to $70 \%$.

Before and after the irradiation, current-voltage $(I-V)$ characteristics of all optoelectronic devices were measured in highly controlled conditions at room temperature. During the measurement, the samples were removed from the experimental room after absorption of the anticipated dose of radiation. There have been undertaken three measurements of the $I-V$ characteristics:

(1) first measurement: immediately before neutron irradiation,

(2) second measurement: immediately after neutron irradiation,

(3) third measurement: 1 month after neutron irradiation.

The third measurement has been undertaken one month after the irradiation, in order to give enough time for sample 


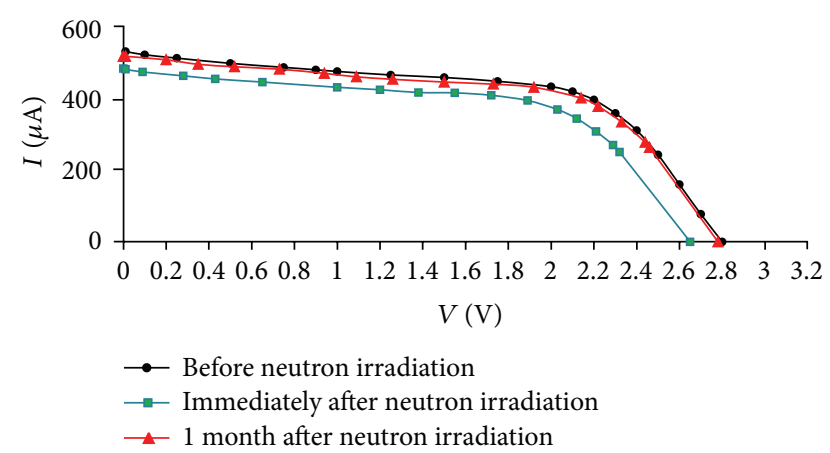

FIgURE 1: $I-V$ characteristics of the solar panels before and after neutron irradiation.

recovery. For this reason, the changes occurring in the samples can be considered permanent. Standard measurement equipment was used to measure $I-V$ curve. The professional digital multimeter Amprobe 33XR was used for the current measurement. Combined measurement uncertainty for all measurements was less than $1.2 \%$ [12-15]. Measurements of $I-V$ characteristics have been performed for illumination levels of $10 \mathrm{~W} / \mathrm{m}^{2}$ (for phototransistors BPW40), $4.32 \mathrm{~W} / \mathrm{m}^{2}$ (for solar panels), and $0.45 \mathrm{~W} / \mathrm{m}^{2}$ (for phototransistors LTR4206 and all photodiodes, BP104, BPW41N, BPW34, and SFH203FA).

\section{Results and Discussion}

I-V characteristics of optoelectronic devices before and after the neutron irradiation are shown in Figure 1 (solar panels), Figure 2 (reverse biased photodiodes), and Figure 3 (phototransistors). They all behaved in a similar way; neutron radiation decreased their photocurrent and, after that, the annealing process increased it. The extent of their damage and efficiency of their annealing process are different from one type of devices to another. Neutron radiation had the least impact on solar panels and the most on phototransistors. At the solar panels, the recovery process was also the most effective, while it has achieved the poorest results on photodiodes (Figures 1 to 3 ).

The fundamental "structural" element of solar (PVphotovoltaic) systems, the solar cell, is usually based on the $\mathrm{p}-\mathrm{n}$ junction device that, exposed to solar radiation, gives power as its output characteristic. Radiation damage due to neutrons is primarily connected to the displacement of silicon atoms from their lattice sites in the crystalline silicon solar cells, leading to the destruction and distortion of local lattice structure and formation of defects. If, under the influence of neutrons, stable defects are made, they could, together with impurity atoms, donors, and, for example, implanted atoms, form complex defects acting as recombination sites or traps, significantly decreasing minority carrier lifetime. This lifetime decrease produces the degradation of the electrical parameters of the cell, such as series resistance $\left(R_{s}\right)$, output current, and finally efficiency $(\mu)$. The interaction between vacancies, self-interstitials, impurities, and dopants in Si leads to the formation of undesirable point defects such as recombination and compensator centers which affect performance of solar cells, especially in space. The introduction of radiationinduced recombination centers reduces the minority carrier lifetime in the base layer of the p-n junction increasing series resistance. Factors that influence the internal parameters of solar cells such as series and parallel resistance lead to changes in efficiency and maximum generated power in a solar cell [16].

High-energy particles like neutrons create much more displacement damages than gamma radiation. When an atom is ejected from its position, it creates a vacancy in the lattice. The ejected atom may recombine with a vacancy or stay in an interstitial position in the lattice. The vacancies are mobile and combine with other vacancies or with impurities of the semiconductor [17, 18]. Sporea et al. [19] have calculated that the major degradation of the photodiode responsivity, for the total gamma dose of $1.23 \mathrm{MGy}$ and to the neutron fluence of $1.2 \times 10^{13} \mathrm{n} / \mathrm{cm}^{2}$, occurs in the case of neutron irradiation (37.5\%) as compared to the gamma irradiation (7.2\%).

Phototransistors are susceptible to neutron radiation. Neutron radiation affects phototransistors performance primarily by creating lattice defects, which can dramatically increase carrier recombination rate. In turn, the increase in recombination rate degrades the current gain. Many studies of displacement damage mechanisms in bipolar transistors have indicated that the common-emitter current gain degrades through the introduction of recombination centers. Measurement data of phototransistors before and after radiation indicate that the effect of neutron damage is most pronounced on the base current of the transistors. The phototransistor is a light-controlled device in which the base current, that is, light controls the output collector current. Fast neutrons primarily cause cluster defects and are the dominant radiation-induced damage mechanism in phototransistor. The number of atomic displacements caused by neutrons is very large. The result is the formation of recombination-generation centers. Electron-hole recombination causes reductions in current gain and switching times. Electron-hole generation causes an increase in leakage current. Majority carrier removal and decreases in carrier mobility cause increases in forward collector-emitter voltage. The current gain is determined by the fraction of majority carriers emitted by the emitter that pass through the base as minority carriers and collected as majority carriers by the collector. An increase in recombination-generation center density due to radiation-induced defects causes a decrease in minority carrier lifetime so that the rate of electron-hole recombination increases in the base. Thus, the current gain decreases as the fraction of emitter-injected carriers reaching the collector decreases so that photocurrent decreases [20].

For this research, the long-term isothermal annealing at room temperature was used. The vacancies and interstitials are quite mobile in silicon at room temperature and hence, are referred to as unstable defects. After vacancy introduction by irradiation, vacancies move through the lattice and form more stable defects, such as divacancies and vacancy-impurity complexes. When electrical properties 


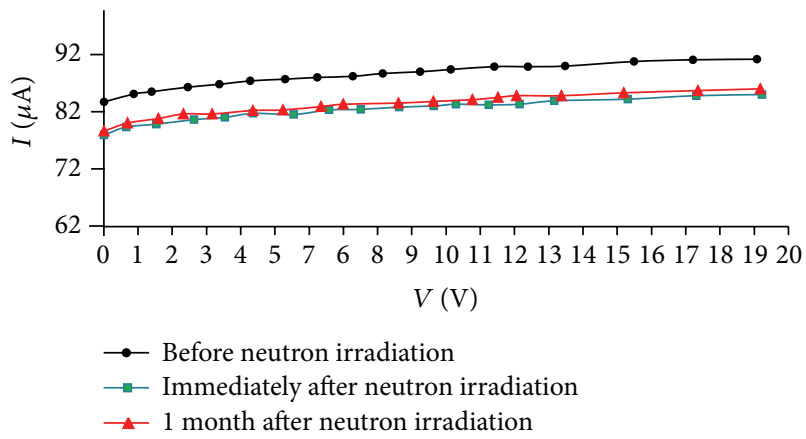

(a) Photodiode BP104

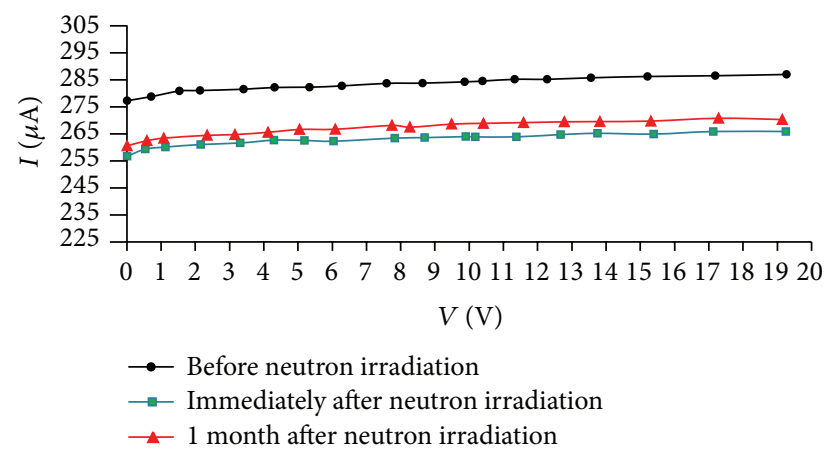

(c) Photodiode BPW34

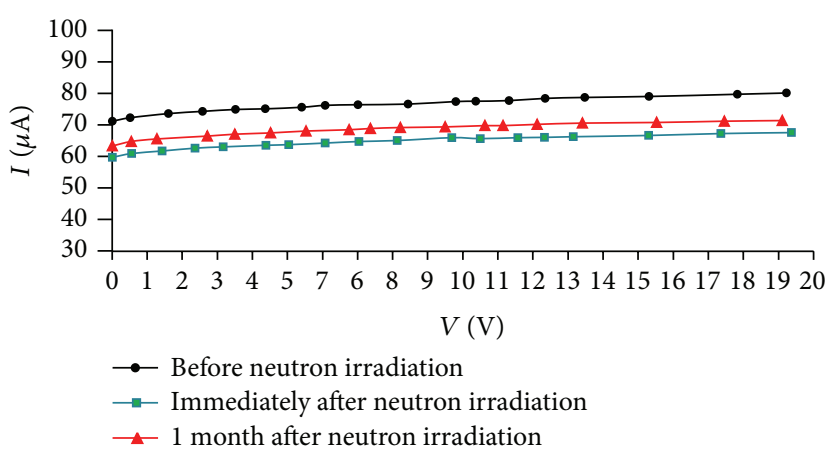

(b) Photodiode BPW41N

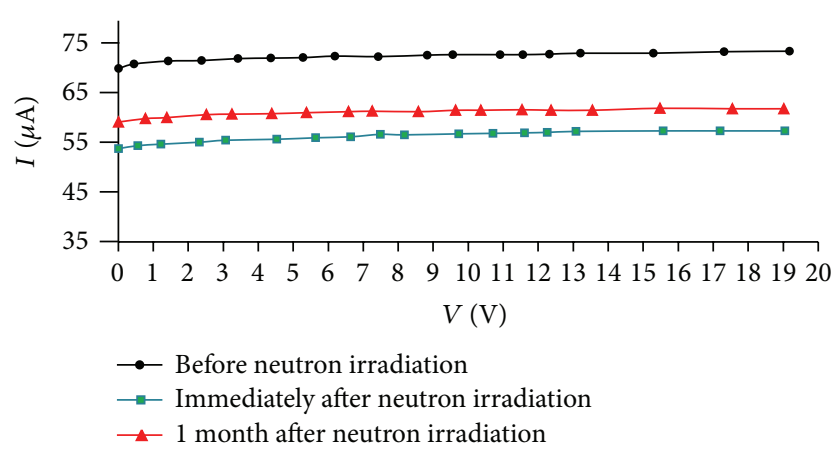

(d) Photodiode SFH203FA

FIGURE 2: $I-V$ characteristics of the reverse biased photodiodes before and after neutron irradiation.

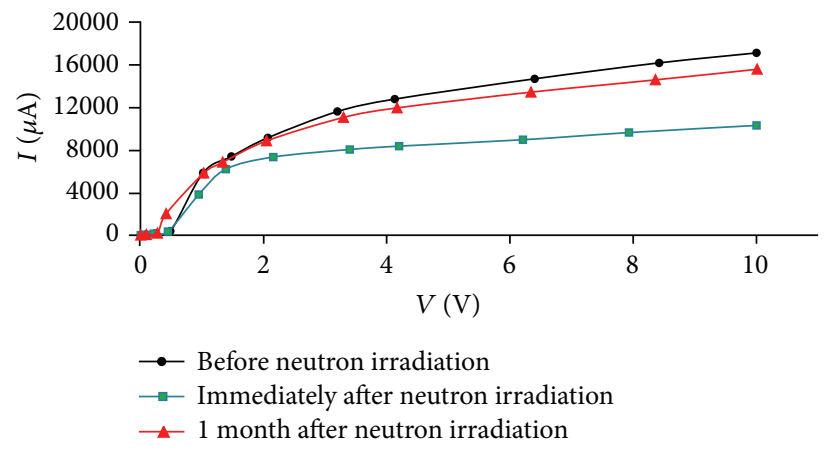

(a) Phototransistor LTR4206

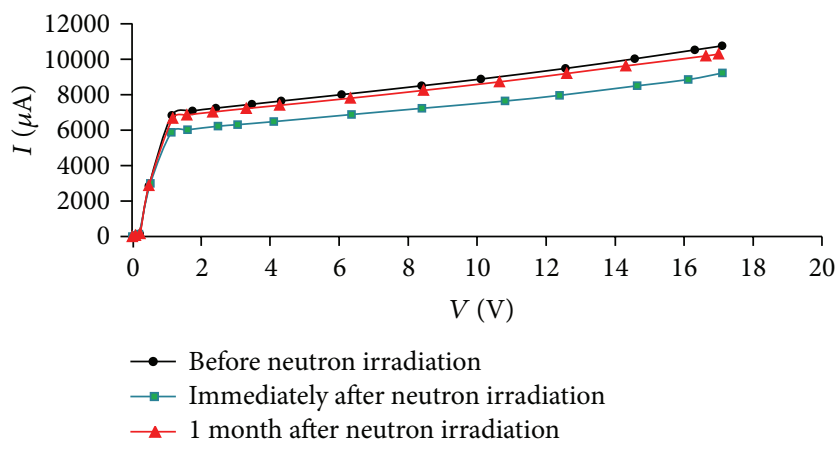

(b) Phototransistor BPW40

FIGURE 3: $I$ - $V$ characteristics of the phototransistors before and after neutron irradiation.

are monitored during this defect rearrangement (or annealing) process, a decrease in the effectiveness of the damage with increasing time is typically observed [10]. Moll [21] describes the enhancement of the effective doping concentration for the longer annealing times. Feick [22] observed this phenomenon at room temperature. During the process of annealing, defects cluster and some electrical inactive defects become active in a cluster. From the standpoint of the photocurrent intensity before irradiation and after annealing process, best results have been achieved in the solar panels. Radosavljević and Vasić [23] observed an increase of the maximum power for lower values of irradiation. They proposed the following explanation that small doses of radiation may produce a decrease in series resistance.
Subsequently, this will lead to a lowering of the noise level and an increase in the output current since, as is well known, high series resistance of a solar cell is one of the main limiting factors of its efficiency. Since the rate of damage recovery from annealing in solar panels is almost the same as the rate of damage creation (Figure 1), for lower values of neutron irradiation, it is possible to use annealing as a part of a hardening method [17, 18, 24, 25].

Solar cells have attracted much attention as good candidates for low cost, good stability, and high efficiency. There are many researches in this emerging technology in order to investigate the behavior of solar cells in various working conditions [26-29]. Solar cells have proved to be very reliable devices regardless of the environment in which they exist. 
This experiment showed that, even under conditions of increased neutron radiation, solar cells were able to recover their characteristics almost to the level before the radiation and that makes them dominant over conventional optoelectronic devices.

\section{Conclusion}

The effect of neutron radiation on optoelectronic devices, solar panels, and photodiodes phototransistors has been observed in this paper. Neutron radiation is considered to be one of the most severe of all types of radiation experienced in space as it can cause biological damage. It represents approximately $30 \%$ of the total exposure for those aboard the ISS. In space, neutrons are produced when charged particles collide with physical matter, such as the walls and equipment on the ISS. Therefore, it is important to give a review of the effectiveness of optoelectronic devices in the enviroment with neutron radiation, that is, space. According to current theories, neutron irradiation in all samples caused degradation of their structure and deterioration of the output characteristics. Solar panels have proved to be most resistant to the effects of neutrons. And annealing process for them had the best effect. The reason for that could be the construction of a solar panel. To obtain the maximum power voltage of panels $(4 \mathrm{~V})$, a large number of individual cells are used in series and parallel combinations. According to the degree of recovery in the annealing process, one can conclude that, for working in the environment of increased neutron radiation, solar panels and phototransistors preferable than photodiodes.

\section{Acknowledgment}

The Ministry of Education, Science and Technological Development of the Republic of Serbia supported this work under Contract 171007.

\section{References}

[1] H. Johnston, "Radiation damage of electronic and optoelectronic devices in space," in Proceedings of the 4th International Workshop on Radiation Effects on Semiconductor Devices for Space Application, Tsukuba, Japan, October 2000.

[2] S. J. Watts, J. Matheson, I. H. Hopkins-Bond, A. HolmesSiedle, A. Mohammadzadeh, and R. Pace, "A new model for generation-recombination in silicon depletion regions after neutron irradiation," IEEE Transactions on Nuclear Science, vol. 43, no. 6, pp. 2587-2594, 1996.

[3] M. B. El-Mashade, M. Ashry, S. M. Eladl, and M. S. Rageh, "Experimental measurements of some optoelectronic devices before and after gamma irradiation," Journal of Microwaves and Optoelectronics, vol. 3, no. 6, pp. 1-12, 2004.

[4] Z. D. Kovalyuk, V. N. Katerynchuk, O. A. Politanska, O. N. Sydor, and V. V. Khomyak, "Effect of gamma radiation on the properties of InSe photodiodes," Technical Physics Letters, vol. 31, no. 5, pp. 359-360, 2005.

[5] M. Vujisić, K. Stanković, N. Marjanović, and P. Osmokrović, "Simulated effects of proton and ion beam irradiation on titanium dioxide memristors," IEEE Transactions on Nuclear Science, vol. 57, no. 4, pp. 1798-1804, 2010.

[6] M. Vujisić, K. Stanković, E. Dolićanin, and P. Osmokrović, "Radiation hardness of COTS EPROMs and EEPROMs," Radiation Effects and Defects in Solids: Incorporating Plasma Science and Plasma Technology, vol. 165, no. 5, pp. 362-369, 2010.

[7] D. R. Alexander, "Transient ionizing radiation effects in devices and circuits," IEEE Transactions on Nuclear Science, vol. 50, no. 3, pp. 565-582, 2003.

[8] B. D. Iričanin and D. M. Gvozdić, "The analytic approach in the modelling of one-dimensional electron concentration distribution in some two-valley semiconductor electron devices," Journal of Physics A, vol. 31, no. 13, pp. 2997-3017, 1998.

[9] S. Stanković, B. Iričanin, D. Nikolić et al., "MSV signal processing system for neutron-gamma discrimination in a mixed field," Nuclear Technology and Radiation Protection, vol. 27, no. 2, pp. 165-170, 2012.

[10] J. R. Srour, C. J. Marshall, and P. W. Marshall, "Review of displacement damage effects in silicon devices," IEEE Transactions on Nuclear Science, vol. 50, no. 3, pp. 653-670, 2003.

[11] C. L. Axness, B. Kerr, and E. R. Keiter, "Analytic 1-D pn junction diode photocurrent solutions following ionizing radiation and including time-dependent changes in the carrier lifetime from a nonconcurrent neutron pulse," IEEE Transactions on Nuclear Science, vol. 57, no. 6, pp. 3314-3321, 2010.

[12] K. D. Stanković, "Influence of the plain-parallel electrode surface dimensions on the type a measurement uncertainty of GM counter," Nuclear Technology and Radiation Protection, vol. 26, no. 1, pp. 39-44, 2011.

[13] Ć. Dolićanin, K. Stanković, D. Dolićanin, and B. Lončar, "Statistisal treatment of nuclear counting results," Nuclear Technology and Radiation Protection, vol. 26, no. 2, pp. 164-170, 2011.

[14] K. Stanković, M. Vujisić, D. Kovačević, and P. Osmokrović, "Statistical analysis of the characteristics of some basic massproduced passive electrical circuits used in measurements," Measurement, vol. 44, no. 9, pp. 1713-1722, 2011.

[15] M. Vujisić, K. Stanković, and P. Osmokrović, "A statistical analysis of measurement results obtained from nonlinear physical laws," Applied Mathematical Modeling, vol. 35, no. 7, pp. 31283135, 2011.

[16] M. Zdravković, A. Vasić, R. Radosavljević, M. Vujisić, and P. Osmokrović, "Influence of radiation on the properties of solar cells," Nuclear Technology and Radiation Protection, vol. 26, no. 2, pp. 158-163, 2011.

[17] A. Holmes-Siedle and L. Adams, Handbook of Radiation Effects, Oxford Science, 1993.

[18] G. C. Messenger and M. S. Ash, The Effects of Radiation on Electronic Systems, Van Nostrand Reinhold, New York, NY, USA, 2nd edition, 1991.

[19] D. G. Sporea, R. A. Sporea, C. Oproiu, and I. Vatǎ, "Comparative study of gamma-ray, neutron and electron beam irradiated index-guided laser diodes," in Proceedings of the 8th European Conference on Radiation and Its Effects on Components and Systems (RADECS '05), pp. PA31-PA39, September 2005.

[20] G. E. Schwarze and A. J. Frasca, "Neutron and gamma irradiation effects on power semiconductor switches," in Proceedings of the 25th Intersociety Energy Conversion Engineering Conference (IECEC '90), vol. 6, pp. 30-35, August 1990.

[21] M. Moll, Radiation damage in silicon particle detectorsmicroscopic defect and macroscopic properties [Ph.D. thesis], University of Hamburg, Hamburg, Germany, DESY-THESIS1999-040. 
[22] H. Feick, Radiation tolerance of silicon particle detectors for highenergy physics [Ph.D. thesis], University of Hamburg, Hamburg, Germany, 1997, Internal Report, DESY F35D-97-08.

[23] R. Radosavljević and A. Vasić, "Effects of radiation on solar cells as photovoltaic generators," Nuclear Technology and Radiation Protection, vol. 27, no. 1, pp. 28-32, 2012.

[24] D. Nikolić, A. Vasić, I. Fetahović, K. Stanković, and P. Osmokrović, "Photodiode behavior in radiation environment," Scientific Publications of the State University of Novi Pazar A, vol. 3, no. 1, pp. 27-34, 2011.

[25] M. Vujisić, N. Marjanović, I. Fetahović, K. Stanković, and P. Osmokrović, "Influence of radiation on titanium dioxide mermistors," Scientific Publications of the State University of Novi Pazar A, vol. 4, no. 1, pp. 75-82, 2012.

[26] M. J. Jeng, Y. L. Wung, L. B. Chang, and L. Chow, "Particle size effects of $\mathrm{TiO}_{2}$ layers on the solar efficiency of dye-sensitized solar cells," International Journal of Photoenergy, vol. 2013, Article ID 563897, 9 pages, 2013.

[27] Y. Yamamoto, Y. Aoyama, S. Shimizu, J. Kano, F. Saito, and S. Ito, "Influence of titania dispersivity on the conversion efficiency of dye-sensitized solar cells," International Journal of Photoenergy, vol. 2011, Article ID 234931, 7 pages, 2011.

[28] H. Boo, J. Lee, M. G. Kang et al., "Effect of high-temperature annealing on ion-implanted silicon solar cells," International Journal of Photoenergy, vol. 2012, Article ID 921908, 6 pages, 2012.

[29] M. I. Kabir, S. A. Shahahmadi, V. Lim, S. Zaidi, K. Sopian, and N. Amin, "Amorphous silicon single-junction thin-film solar cell exceeding $10 \%$ efficiency by design optimization," International Journal of Photoenergy, vol. 2012, Article ID 460919, 7 pages, 2012. 

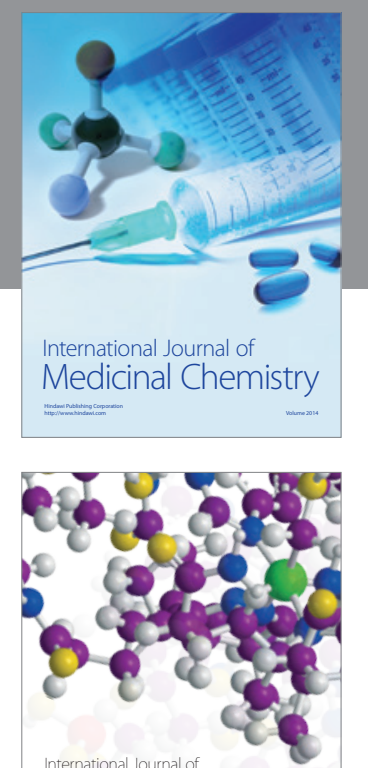

\section{Carbohydrate} Chemistry

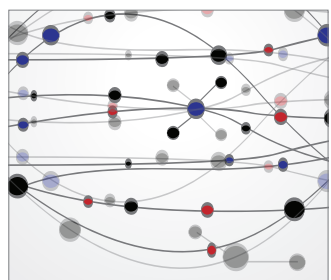

The Scientific World Journal
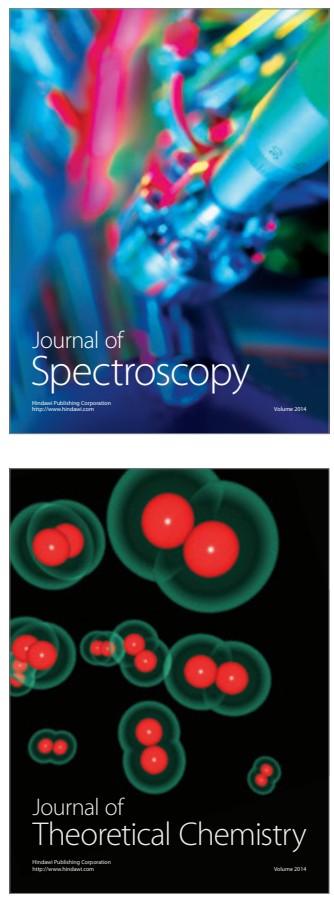
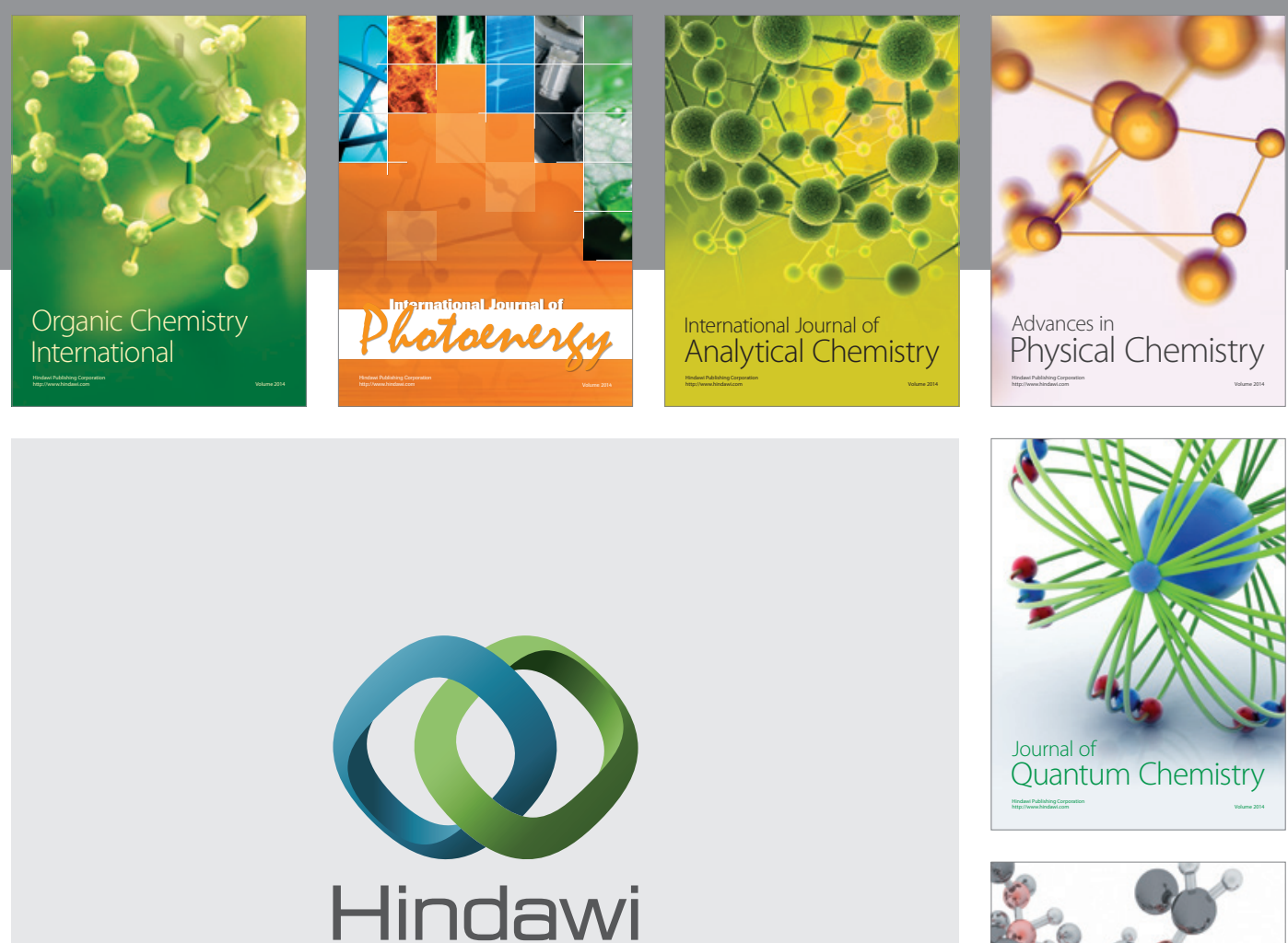

Submit your manuscripts at

http://www.hindawi.com

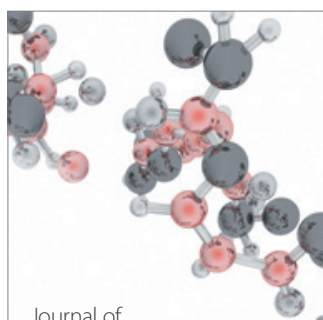

Analytical Methods

in Chemistry

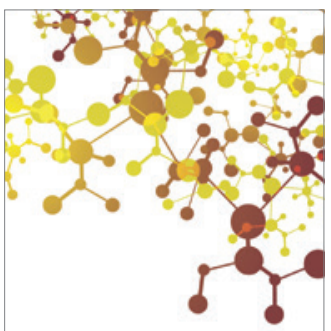

Journal of

Applied Chemistry

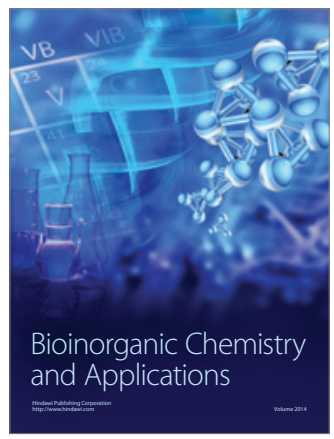

Inorganic Chemistry
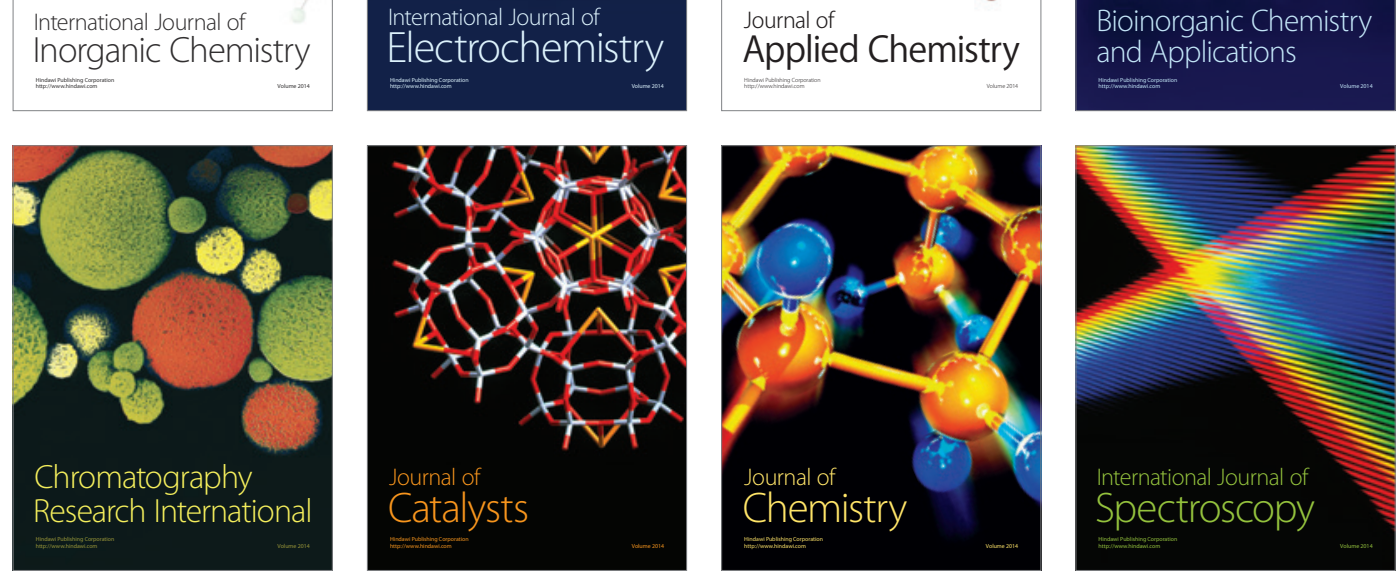